\title{
ORÇAMENTOS PARTICIPATIVOS E INSTITUIÇÕES PARTICIPATIVAS ASPECTOS PARA A AVALIAÇÃO DE EXPERIÊNCIAS E CASOS ${ }^{1}$
}

\author{
Valdemir Pires \\ Carmen Pineda Nebot*
}

Resumo: Discute as perspectivas avaliativas a partir das quais é possível e conveniente avaliar os Orçamentos Participativos (OPs) e as instituições participativas (IPs) que vêm sendo experimentados no Brasil desde as duas últimas décadas do século passado. É proposto um enfoque integrado de avaliação dos OPs e IPs, com vistas a evitar conclusões parciais e enviesadas, mormente as que se pautam exclusivamente ou preponderantemente por metodologias quantitativas. Esta discussão se faz necessária na medida em que, nos últimos cinco anos, a crítica a essas experiências vem ganhando espaço. Por meio da reflexão críticocriativa, de natureza ensaística, e com base na literatura recente sobre o tema, conclui-se pela necessidade de adotar, nas avaliações empíricas, o mencionado enfoque integrado de avaliações dos OPs e IPs; conclui-se, também, que é fundamental, para o avanço teórico sobre o tema, dedicar especial atenção ao critério da desejabilidade da adoção da participação popular nas decisões governamentais sob democracia representativa, uma vez que existe teoria (public choice) que a refuta, assim como teoria (neorrepublicanismo) que a acolhe.

Palavras-chaves: Orçamento participativo. Instituições participativas. Democracia deliberativa. Inovação institucional. Participação popular.

\begin{abstract}
This article is to discuss the evaluative perspectives from which it is possible and convenient evaluate the Participatory Budgets (PBs) and the participatory institutions (PIs) that are being experienced in Brazil since the last two decades of the last century. It is proposed an integrated perspective of evaluation of PBs and PIs, in order to avoid partial and biased conclusions, especially those which are based solely or primarily on quantitative methodologies. This discussion is necessary since, in the past five years, the criticism of these experiments has been increasing. Through critical and creative reflection, in essay form, and based on the recent literature on the topic, it is concluded by the need to adopt, in the empirical evaluation, an integrated approach of evaluation of the PBs and the PIs, such as it is proposed in this article. It is conclude also which is fundamental for the theoretical advancement on the subject dedicate special attention to the desirability or not of adopting the criterion of popular participation in government decisions under representative democracy, since it is refuted by public choice and defended by neo-republicanism.
\end{abstract}

Keywords: Participatory budgeting. Participatory institutions. Deliberative democracy. Institutional innovation. Popular participation.

\footnotetext{
${ }^{1}$ Os autores agradecem os comentários e sugestões oferecidos pelos participantes do II Congreso Internacional en Gobernanza y Asuntos Públicos: Gestion de la Escasez: Participación, Territorios y Estado del Bienestar (Universidad Complutense de Madrid/Instituto de Ciencia de La Administración).

*Valdemir Pires é economista, professor do Departamento de Administração Pública da UNESP/Araraquara SP, líder do Grupo de Pesquisa sobre Controle Social do Gasto Público (pires.valdemir@gmail.com). Carmen Pineda Nebot é consultora de Administrações Públicas na Espanha, membro do Grupo de Pesquisa sobre Controle Social do Gasto Público (carmenpinedanebot@hotmail.com).
} 


\section{Introdução}

Ao longo do período compreendido pelas duas últimas décadas do século $\mathrm{XX}$ e pela primeira década do século XXI, o Brasil passou por profundas transformações sociais e políticas. Saindo de um regime ditatorial-militar que perdurou de 1964 a 1985, o país retornou à democracia, graças à força de grandes mobilizações populares e sindicais (que tiveram como ponto alto o movimento por eleições “diretas-já”), mudou sua Constituição (1988), ampliou direitos políticos e sociais, promoveu reformas do Estado e alterou o modus operandi das administrações públicas, tornando-as (ainda que não suficientemente) mais transparentes e permeáveis aos interesses populares (DAGNINO, 2002; BRESSER-PEREIRA; WILHEIM; SOLA, 1999). A participação popular - apesar de inicialmente proibida por razões de "segurança nacional" - foi intensa no período de transição da ditadura para a democracia e depois, uma vez consolidado o novo regime, tornou-se, primeiramente, uma prática quotidiana das populações urbanas, na sua relação com os poderes constituídos, e, num segundo momento, um direito inscrito na Constituição e nas leis federais, estaduais e municipais.

As experiências de orçamento participativo (OP) estiveram entre as práticas pioneiras de participação popular nos processos decisórios governamentais, seguidas de outras instituições participativas (IPs) ${ }^{2}$, como os conselhos gestores municipais de políticas públicas (CGMPPs). As IPs, em geral (entre as quais não só os CGMPPS, mas também os planos diretores municipais participativos, as comissões tripartites, as audiências públicas e conferências nacionais, estaduais e municipais sobre diversos temas e questões ${ }^{3}$ ), e os OPs, como um tipo específico e notório de IP, se constituem na experiência brasileira de pouco mais de duas décadas de inovação institucional de cunho democrático. E agora começam a ser questionadas e avaliadas sob parâmetros cada vez mais rigorosos, até porque, passada a fase eufórica de sua implementação, o ânimo participativo arrefeceu (sob os ventos desalentadores de um período que bem merece o epíteto de neoliberal) e as promessas não cumpridas e expectativas frustradas vão se acumulando.

Num contexto de quase-consenso, tanto político quanto acadêmico, em torno do protagonismo cidadão e da participação popular em decisões governamentais e na gestão de políticas públicas, sustentado em meio a um clima de baixa propensão dos indivíduos ao envolvimento com assuntos governamentais, partidários, sindicais e eleitorais, o foco das avaliações das IPs recai sobre a sua efetividade (AVRITZER, 2011), justamente por causa do hiato que muitas vezes se verifica, atualmente, entre o discurso e a prática, nesses assuntos.

Não obstante o acerto de se atentar para a efetividade, na avaliação das IPs, é muito importante considerar outras dimensões, como as da eficiência, da eficácia, da sustentabilidade,

\footnotetext{
2 A expressão "instituições participativas" é utilizada, aqui, na acepção de Avritzer (2008, p. 45): "formas diferenciadas de incorporação de cidadãos e associações da sociedade civil na deliberação sobre políticas."

${ }^{3}$ Não são aqui considerados o plebiscito, o referendo e a iniciativa popular (previstos na Constituição brasileira de 1988) porque, apesar de importantes conquistas, foram pouco utilizados.
} 
da replicabilidade e da desejabilidade. É sobre esses diversos focos da avaliação dos OPs e IPs que se detém este estudo, dividido em três partes. Depois de um breve comentário sobre a evolução dos OPs e IPs no Brasil nas últimas três décadas (seção 1), são discutidos cada um dos supramencionados focos de avaliação (seção 2), assim como uma visão integrada dos mesmos (seção 3), detendo-se a análise na dimensão da desejabilidade, a fim de remeter a um debate teórico relevante (entre adeptos da public choice e do neorrepublicanismo), por permitir a contraposição de duas visões de mundo opostas sobre a democracia, uma esposada por economistas, de um lado, e outra, preferida por cientistas políticos, de outro lado.

\section{Ondas de OPs e IPs no Brasil transitando do século XX para o século XXI}

Os levantamentos mais abalizados reportam a seguinte evolução na quantidade de OPs no Brasil, desde o momento em que teve início em Porto Alegre ${ }^{4}: 13$ no mandato municipal 1989-1992, 53 no mandato 1993-1996 e 140 no mandato 1997-2000 (RIBEIRO e GRAZIA, 2003); 190 no mandato 2001-2004 e 201 no seguinte (2005-2008), conforme constataram Avritzer e Wampler (2008). Esses números são aproximativos, pois há variações metodológicas e procedimentais nos casos identificados, com diferenças nos resultados e no alcance. Não tem sido possível um estudo minucioso que possa averiguar a validade das declarações de protagonistas $^{5}$ (e, portanto, interessados) em que se basearam os levantamentos, ou proceder a análises documentais e de grupos de protagonistas do governo e da sociedade civil, restando trabalhar com esses números e confiar mais firmemente em outros, menores, relacionados a experiências amplamente difundidas, conhecidas e estudadas, tomando como paradigmáticas a pioneira, de Porto Alegre-RS e a de Belo Horizonte-MG (diferente, mas bastante intensa, como atestam os estudos), ou até mesmo as 20 que perduraram por pelo menos três mandatos consecutivos ou alternados, listadas por Costa (2010).

Numerosos casos de OP menos notórios do que os identificados por Costa (2010) já foram objeto de estudos em programas de pós-graduação no Brasil ${ }^{6}$, facilitando o mapeamento das experiências, mas nem sempre possibilitando avaliações mais aprofundadas, uma vez que as

\footnotetext{
${ }^{4}$ Antes de Porto Alegre, conforme Pires (2001), existiram poucas cidades brasileiras que desenvolveram experiências semelhantes ao OP, porém com pouca repercussão, menores resultados e horizontes temporais mais curtos. Poderiam ser chamados de casos precursores de OP. Entre eles, Vila Velha (ES), Piracicaba (SP), Lajes (SC) e Boa Esperança (SC).

${ }^{5}$ Torres e Grazia (2003) aplicaram questionários a 103 agentes envolvidos com práticas autodenominadas Orçamento Participativo, das 140 inicialmente identificadas, referentes a 1997-2000. Elas alertam que a pesquisa foi realizada levando-se em conta também uma "dimensão-projeto" do OP, que impede uma leitura totalmente isenta das respostas obtidas. Elas informam que os números referentes aos dois mandatos municipais anteriores foram obtidos em cadastros do Fórum Nacional de Participação Popular nas Administrações Municipais, grupo de interessados em ampliar e consolidar o OP no Brasil, a partir de postos ocupados em governos locais. Avritzer e Wampler (2008) tiveram oportunidade de realizar um trabalho mais detido (por manusearem um banco de dados prévio, mais sólido e consistente e por adotarem procedimentos do tipo snow-balling junto a governos e instituições, aproveitando-se de acúmulos de pesquisa anteriores), mas mesmo assim trabalharam com a aplicação de questionários.

${ }^{6}$ Pires e Martins (2011) identificaram quase três dezenas de estudos em programas de pós-graduação brasileiros.
} 
metodologias e as bases empíricas utilizadas nas pesquisas são muito heterogêneas e nem sempre confiáveis, dependendo do que se queira avaliar.

A literatura brasileira mais recente sobre IPs tem se dedicado mais frequentemente ao estudo dos CMGPPs, devido à sua disseminação por todo o país e sua permanência assegurada por lei e, também, por causa da redução do ímpeto expansionista dos OPs. Conselhos de Saúde e de Educação são os que mais chamam a atenção dos estudiosos (GOHN, 2001; TATAGIBA, 2002; GUIMARÃES, 2009; VAZ, 2011, por exemplo). Santos Jr., Ribeiro e Azevedo (2004) procuraram evidenciar a evolução dos conselhos no Brasil recente; segundo a Pesquisa de Informações Básicas Municipais (MUNIC), realizada pelo Instituto Brasileiro de Geografia e Estatística (IBGE), os Conselhos de Saúde existem em 100\% dos municípios brasileiros, enquanto que os de Educação e de Assistência Social atingem 90\% deles.

OPs e CMGPPs são as principais modalidades de IPs experimentadas no Brasil nas últimas três décadas. É interessante observar que os OPs ganharam espaço durante a redemocratização do país, fazendo parte de uma onda (a primeira) de inovações "movimentalistas" (decorrentes da mobilização popular do período 1975-1990), enquanto que os CMGPPs se fortaleceram um pouco depois da Constituição de 1988, com o país já democratizado e sob pressão para a reforma do Estado (segunda onda), adquirindo uma feição mais "gerencialista" (PIRES, 2009). Os diferentes contextos em que surgiram os OPs e CMGPPs e os distintos motes político-administrativos que os impulsionaram são elementos fundamentais (talvez pressupostos) a serem levados em conta quando se deseja avaliar as práticas correspondentes a uns e outros. Não é à toa que os CMGPPs nasceram por força de lei e que os OPs se moveram e se movem à base de autorregulação: a natureza e o grau de institucionalização de uns e de outros explicita em boa medida a proeminência de uma lógica "movimentalista" (em declínio) e de uma lógica governamental (em ascensão).

Antes de se passar à discussão dos focos a partir dos quais é possível e desejável avaliar as IPs no Brasil, convém registrar um posicionamento a respeito da evolução delas. Ao avaliar o acúmulo obtido pelo Brasil em inovações institucionais que contribuíram para a transição democrática, e que contribuem ou podem contribuir para a consolidação da democracia e para a melhoria da gestão pública no país, é fundamental que não se perca de vista que sem as práticas participativas adotadas pelos cidadãos e organizações da sociedade civil ao longo das três últimas décadas, malgrado seus eventuais insucessos em tópicos específicos e isolados, a feição social, política e institucional brasileira seria bem outra, muito provavelmente pior. As metodologias e pressupostos de avaliações que desconsiderem este fato correm o risco de, no afã de cotejar causas e efeitos de modo supostamente científico, identificar somente pontos de sucesso e insucesso numa trajetória bem-sucedida no conjunto, porque mudou em profundidade o tipo de relacionamento entre os governos e as administrações públicas e os cidadãos, eleitores e contribuintes. 
Além do cuidado de considerar conquistas históricas de conjunto (perceptíveis, mas não mensuráveis), e não apenas resultados imediatos e cientificamente comprováveis, as avaliações dos OPs e das IPs precisam também, para contribuir para o avanço do conhecimento e para a melhoria das práticas, levar em conta que lidam com a sociedade em movimento, pautando-se os indivíduos e grupos atuantes por ideias hegemônicas e contra-hegemônicas, que produzem o novo de modo incontrolável e muitas vezes insondável e, portanto, precariamente analisável, enquanto este novo não se torna relativamente velho, sedimentado. De fato, IPs inovadoras raramente são, pois transitam no devir, dificilmente captado por análises, abordagens, metodologias e avaliações que não se deixam penetrar pela visão dialética da realidade.

\section{OPs e IPs: os enfoques da eficiência, da eficácia, da efetividade, da sustentabilidade, da replicabilidade e da desejabilidade para sua avaliação}

Os OPs e os CGMPPs são as modalidades de IP mais disseminadas na administração pública brasileira e as avaliações dessas experiências são as que maior contribuição pode trazer para a compreensão das IPs no Brasil e para o aperfeiçoamento das práticas avaliativas dessas inovações institucionais tidas como promissoras.

Toda e qualquer avaliação que se leve a efeito tem, necessariamente, uma finalidade, e é feita por atores nela interessados por diferentes razões. Assim, o enfoque adotado em uma avaliação específica terá sempre a marca das condições sob as quais foi ou será efetivada. Uma agência de fomento avaliará para saber se deve ou não continuar apoiando uma prática por ela exigida como condição para financiar projetos; partidos, políticos e governantes eleitos avaliarão para prospectar as vantagens e desvantagens obtidas com os mecanismos de participação por eles patrocinados; uma ONG interessada em promover relacionamentos solidários em comunidades carentes poderá querer avaliar as mudanças de comportamento propiciadas por um projeto de construção de moradias por meio de mutirão comunitário etc. Conforme o objetivo da avaliação a ser feita, e a visão de processo avaliativo de que se lance mão para se proceder a esta avaliação, serão distintos o enfoque e a metodologia utilizados. É importante, em todos os casos, que se tenha uma visão de conjunto dos enfoques possíveis para que se chegue a avaliações adequadas e aceitáveis. Alguns enfoques relevantes são apresentados nas subseções seguintes e são retomados em conjunto, de forma integrada, na seção 3 .

\subsection{Realidade dos OPs e CGMPPs}

Nem todas as práticas auto-enquadradas ou precariamente identificadas como pertencentes ao universo das IPs, ou como OPs, desfrutam da elementar condição de realidade. Existem "factóides", que ao invés de serem avaliados, precisam, mesmo, ser desmascarados.

\footnotetext{
${ }^{7}$ Divulgação do que não é como se fosse e tivesse importância; uma mentira propagandeada com alarde para chamar ou desviar a atenção do público.
} 
Eles existem porque no mundo da política são úteis. Num contexto de disputa, em que uma ideia é amplamente aceita, raros serão os que a atacarão ${ }^{8}$, sob pena de perda de espaço, apoio ou votos. Enquanto organismos multilaterais, ONGs e a mídia convencerem os eleitores de que OPs e IPs são caminhos para democracia mais ampla, governos mais eficientes e políticas públicas inclusivas, até que se prove o contrário detentores de cargos eletivos se dirão comprometidos com eles e muitos simularão na prática algo próximo ou similar, persistindo até a onda de credibilidade perder impulso ${ }^{9}$. Portanto, ao considerar as dimensões eficiência, eficácia, efetividade, sustentabilidade, replicabilidade e desejabilidade, a avaliação das IPs e OPs deve, preliminarmente, descartar tudo que não se enquadre no princípio de realidade ou veracidade, que não tenha materialidade nas relações entre o governo e a sociedade civil. Tarefa nem sempre simples, pois a capacidade de simulação e a facilidade para obter apoio são bastante encontradiças em contextos políticos atrasados no que diz respeito às práticas democráticas e republicanas. Tomem-se como exemplos os casos de conselhos municipais de políticas públicas compostos por funcionários públicos, como se fossem representantes da sociedade civil; ou os orçamentos participativos que consistem em apresentar como decisões populares medidas anteriormente decididas pelo prefeito e levadas para assembleias manipuladas ou cooptadas, apenas para serem referendadas. Dada a natureza preliminar (por ser o fenômeno recente) e às vezes precária (pelas condições nas quais ocorrem) dos estudos, análises e avaliações sobre os OPs e sobre os conselhos gestores, comentados na seção anterior, há que se tomar como reais somente os casos mais significativos, a respeito dos quais haja informações seguras. Desses, se pode avaliar com mais confiança a eficiência, a eficácia, a efetividade e a possibilidade de permanência e/ou replicabilidade, assim como a desejabilidade.

\subsection{A eficiência, a eficácia e a efetividade dos OPs e CGMPPs}

A eficiência é um conceito econômico, que relaciona os resultados obtidos aos recursos utilizados, aquilatando, assim, a relação custo-benefício. O funcionamento dos OPs e das IPs implica custos. Estes são as despesas em que se incorre para levar a cabo processos de decisão coletiva, que demandam divulgação, mobilização, oportunização de encontros e eventos, esforços de registro e monitoramento etc.; há também custos de oportunidade, de mais difícil mensuração: o tempo dos participantes, que poderia ser utilizado em outras atividades, mais rentáveis ou mais prazerosas, por exemplo.

\footnotetext{
${ }^{8}$ Pires e Silva (2004) constataram em 1999 - ano de grande divulgação do OP no Brasil e no mundo - o apoio verbal de numerosos políticos a ele, dos mais variados matizes ideológicos; apesar desse apoio, muitos titubearam quando chamados a explicar em que consistia esta metodologia de gestão dos recursos públicos; e outros que estavam em posição que permitiria implantá-lo, nunca o fizeram.

9 A propósito, ver Wampler (2008), que identifica as diferenças de desempenho na implementação de inovações na gestão orçamentária local, relacionadas aos perfis dos agentes que as conduzem: empreendedores de políticas públicas (alto desempenho), defensores de políticas públicas (desempenho limitado) e adotantes formais (desempenho mínimo ou nulo).
} 
Para saber se o OP ou uma IP é eficiente, é preciso, então, relacionar estes custos aos resultados decorrentes. É praticamente impossível fazer este cálculo com precisão, pois existem variáveis de difícil quantificação envolvidas, além de resultados intangíveis ou imperceptíveis no curto prazo. Exemplos: é difícil definir quanto do tempo dos agentes públicos de carreira (da seção de Contabilidade, do Gabinete do Prefeito, por exemplo) envolvidos no OP é custo desta prática inovadora e o quanto é custo decorrente da manutenção das atividades sem que exista o OP - serão os mesmos funcionários, agora com responsabilidades adicionais, não necessariamente dedicando mais tempo aos seus afazeres; não é possível separar os votos de reeleição obtidos por um bom prefeito entre votos ganhos por ele mesmo (decorrentes de seu modo de gerir e de se relacionar com os eleitores) e votos carreados a ele em razão do OP adotado em seu primeiro governo; em que medida a melhora nos indicadores de resultado de políticas públicas compensa os custos de manutenção de estruturas e canais decisórios com participação cidadã é uma pergunta em aberto, pois mesmo que haja uma relação entre esses dados, não é fácil estabelecer a relação custo-benefício.

A eficácia, por seu turno, expressa a capacidade do OP ou de uma IP de atingir certo objetivo ou de cumprir uma definida função. Não se trata, neste caso, de medir cardinalmente: a eficácia pode ser plena ou total, mediana, baixa ou nula. Além disso, a eficácia não se define por si, não é uma relação matemática, como a eficiência: “Eficácia para que?", é sempre preciso perguntar. Uma experiência de OP pode ser ineficaz para melhorar a gestão de recursos financeiros, inicialmente almejada, mas pode ser plenamente eficaz para dar coesão à equipe de governo, cobrada pelo prefeito, em termos de desempenho, a partir da lógica do OP. Isto quer dizer que não se pode falar em eficácia dos OPs e IPs, no singular. Como essas inovações de gestão político-administrativa podem ter impacto sobre numerosas variáveis, internas e externas aos governos, há que se definir sobre qual ou quais delas se deseja conhecer a eficácia, nos procedimentos e processos avaliativos.

Não obstante as já mencionadas - e às vezes insuperáveis - dificuldades para uma plena percepção da eficiência e da eficácia dos OPs e IPs, na prática se trabalha com avaliações aproximativas dessas características empíricas, relacionadas a casos específicos. Certo feeling acaba se estabelecendo entre os participantes, assegurando continuidade ou não das práticas (exceto no caso de IPs legalmente exigidas, que continuam à revelia da eficiência e da efetividade). Por exemplo: após dois ou três anos experimentando o OP, um governo "sente" se as decisões populares estão lhe custando muito ou pouco (em termos de recursos financeiros, materiais e humanos do governo e também em termos de adesão eleitoral); da mesma maneira, sentem os cidadãos participantes se os esforços que fazem compensam ou não, quando comparados às suas expectativas. E a palavra-chave, no caso, é exatamente esta: expectativa. Todos os processos participativos envolvem expectativas, algumas explícitas, outras não. Desse modo, a eficácia dos OPs e IPS consiste em atender expectativas variadas, umas mais, outras 
menos exigentes. A eficiência ocorre quando essas expectativas são minimamente atendidas, ao custo mínimo. A ineficácia é, por definição, inadmissível, tornando um OP ou uma IP insustentável, por indesejável; a ineficiência (alto custo quando comparado ao valor do que se obtém), por sua vez, às vezes é desconsiderada quando há um grau elevado de eficácia no atingimento das expectativas de alguns agentes com poder no processo são atingidas.

Como se pode concluir, entre eficiência e eficácia existe uma relação muito forte, sendo relativamente difícil separá-las para se proceder à avaliação e experiências concretas de OPs e IPs. Nota-se que a verificação da presença dessas qualidades nos OPs e IPs é de fundamental importância.

A efetividade é a qualidade de surtir efeito que as IPs podem ter ou não. Confunde-se facilmente com a eficácia. Para distingui-las, convém destacar que a eficácia está relacionada a resultado, a alvo; enquanto a efetividade diz respeito à capacidade das IPs de atuar, de funcionar (atingindo ou não os objetivos desejados). É efetivo um OP que, tendo por objetivo deliberar sobre metade dos investimentos de um dado ano, com a participação dos representantes das regiões de uma cidade, assim delibera, de fato, mesmo que esta deliberação seja, depois, mal encaminhada pelo governo, tornando-se, portanto, ineficaz. A participação popular terá sido efetiva, mas sem eficácia sobe orçamento público.

A efetividade altera a realidade: algo que existia em potência se materializa. Mas não a altera necessariamente na direção desejada - o que requer a eficácia.

A causa da inefetividade - incapacidade de surtir efeito, portanto - pode, inclusive, ser resultado de baixa eficiência: insuficiente dotação de recursos para obter o resultado almejado; ou aplicação inadequada dos recursos disponibilizados. Exemplo: um CGMPPs com suficiente número de participantes bem dispostos e capacitados para funcionar não tem o respeito do titular da pasta sobre a qual the cabe deliberar e, por isso, não recebe os investimentos necessários em infraestrutura e apoio funcional para atuar. Uma relação custo-benefício inadequada (alto benefício esperado e baixa dotação de recursos), ou seja, uma ineficiência, torna o colegiado inefetivo, com conseqüências negativas também sobre a sua eficácia.

\subsection{A sustentabilidade dos OPs e CGMPPs}

Para ser considerada como tal, uma instituição necessita de um grau de permanência, de aceitação, de uso, pois do contrário não se incorpora aos fazeres, para servir-lhes de referência e funcionar como pólo de aglutinação dos agentes. Sem sustentabilidade não existe instituição, evidentemente. Mesmo que seja por um período limitado: há instituições mais duradouras e instituições menos duradouras.

A sustentabilidade inicial de uma prática é condição sine qua non para que venha a se institucionalizar. Uma lei pode tornar obrigatória uma prática e, assim, contribuir para que ela se torne uma instituição. Pode ocorrer, pelo contrário, que uma prática consagrada pelo uso seja 
sacramentada legalmente. A segunda hipótese consiste num esforço de ampliação e aprofundamento de uma instituição, aumentando suas chances de sustentação ao longo do tempo; a primeira é uma tentativa de forçar a transformação de uma prática em instituição, que pode resultar negativa ou positiva. Ou seja, a lei, pura e simplesmente, não dá sustentabilidade a uma instituição, nem a cria, de fato, principalmente se for uma instituição participativa, já que participação voluntária - como ocorre nos OPs e IPs - não se assegura por decreto ou lei.

A sustentabilidade das experiências de OPs e IPs depende, à revelia de serem ou não exigências legais, de um conjunto de fatores endógenos e exógenos a elas, incluindo, entre outros, como já identificado nos estudos coletados e organizados por Avritzer e Navarro (2003), o desenho institucional, o compromisso político do governo, as características da sociedade civil, a disponibilidade de recursos, a experiência acumulada, a conjuntura política e econômica etc.

As já mencionadas expectativas dos protagonistas e interessados, direta ou indiretamente, nas práticas participativas em processos decisórios governamentais, são também elementos determinantes da sustentabilidade dessas práticas, influenciando, inclusive, nos ciclos altistas e baixistas que às vezes as caracterizam, devido ao influxo de ânimo ou ao de desalento que trazem para os processos e arenas de manifestação e negociação. Além disso, os protagonistas e interessados formam à sua maneira uma percepção da eficiência, da eficácia e da efetividades das IPs que pode contribuir para a sustentabilidade ou não dessas mesmas IPs.

\subsection{A replicabilidade dos OPs e CGMPPs}

IPs que adquirem sustentabilidade, com bons e difundidos resultados, tornam-se com frequência objeto de observação, a fim de serem adotadas em realidades distintas das iniciais, principalmente quando seu escopo abriga aspectos comuns a situações e problemas de mesma natureza ou próxima em comunidades e organizações de diferentes lugares. Passam, então, a ser replicadas, como ocorreu com o OP, a partir dos anos 1990, com base em vários pólos nacionais e internacionais de disseminação da ideia e de apoio às ações para materializá-la.

A replicabilidade, entretanto, às vezes requer adaptações de tal monta que, ao fim e ao cabo, não é obtida, constatando-se na realidade uma IP que ou não funciona, ou não pode ser adequadamente tomada como réplica, inicialmente desejada.

Mesmo quando a reprodução da IP é tornada obrigatória por lei, como é o caso dos CMGPPs no Brasil, a replicabilidade pode ser colocada em questão, pois fazer com que funcionem da mesma maneira nos 5.564 municípios brasileiros, com resultados minimamente próximas entre si, é extremamente difícil. Além disso, tais conselhos se aplicam à realidade federativa brasileira, mas não, talvez, à argentina; e podem ser inimagináveis num país não federativo, como o Chile. O OP, por sua vez, foi um fracasso em Buenos Aires (PERUZZOTI, 
2009), ganhou fisionomia muito distinta da brasileira na Itália (ALEGRETTI, 2009), na Espanha (PINEDA; PIRES, 2011) e em Portugal (DIAS, 2009).

Se o mote da participação comparece compulsoriamente em experiências que recebem o nome de OP ou IP, isso assegura apenas (quando muito) que esforços na direção da democracia participativa estão envolvidos (se de fato estiverem), mas não que se está replicando com sucesso uma IP já testada e aprovada. Há que se averiguar empiricamente.

As principais perguntas a serem feitas, do ponto de vista da replicabilidade, são:

- Antes da experiência: a IP é replicável no novo contexto, pelas mãos dos novos agentes? Os novos agentes são empreendedores de políticas públicas, defensores de políticas públicas ou adotantes formais ${ }^{10}$

- Depois da experiência ou enquanto ela ocorre: trata-se, de fato, de uma réplica? Com que grau de proximidade/perfeição? Se há diferenças entre a experiência original e a atual, elas fortalecem ou enfraquecem a IP?

\subsection{A desejabilidade dos OPs e CGMPPs}

A desejabilidade, nesse contexto, diz respeito não simplesmente à conveniência da adoção de uma IP, mas à percepção dessa conveniência no interior de uma visão de mundo específica da sociedade (e de seu modo de se organizar funcionar), dotada da vontade política de um grupo de atores para promover as mudanças necessárias à adoção dessa IP, ou para evitá-la (no caso da indesejabilidade). Ideia clara e vontade de ação estão presentes no conceito. Mesmo que a clareza e a disposição para agir sejam diferenciadas de ator para ator (cada qual com seus objetivos e estratégias próprios), no conjunto deles existe uma noção de relativo consenso (ou de prevalência de uma dada correlação de força), que resulta em desejabilidade forte, média, fraca ou indesejabilidade, quando se tenta mensurá-la (nunca cardinalmente).

Há duas maneiras de se considerar a desejabilidade: do ponto de vista de um propositor, potencial adotante ou adotante (que pode ter um potencial opositor ou efetivo opositor, ou não); e do ponto de vista das visões de mundo em si, abstratamente consideradas. A distinção é relevante para balizar os tipos de avaliação possíveis sob o enfoque da desejabilidade.

É possível avaliar a desejabilidade dentro de um contexto sociopolítico concreto, procurando identificar o nível de desejabilidade ou indesejabilidade de que são portadores os agentes envolvidos na disputa por implementar ou evitar a implementação de uma IP. Pode ocorrer, por exemplo, que um governo local deseje implantar o OP (mas dentro dele haja setores que, embora não se oponham claramente, no quotidiano, criarão dificuldades para seu funcionamento); que haja segmentos populares favoráveis, mas desejando somente até o ponto em que seus interesses imediatos sejam atendidos (pavimentação de rua, ampliação de escola).

\footnotetext{
${ }^{10}$ Ver nota 8
} 
Assim, a avaliação tenderá a resultar na identificação de uma desejabilidade coletiva insuficiente. Neste exemplo, a avaliação da desejabilidade precisará se alicerçar em dados e informações empíricos, de difícil obtenção, inclusive.

É possível, por outro lado, avaliar a desejabilidade de um ponto de vista estritamente teórico. Por exemplo, colocando frente a frente, visões de democracia nas quais sejam acolhidas as propostas de protagonismo de não eleitos em decisões governamentais e visões de democracia que não acolhem essas propostas. Vale, para ilustrar este tipo de análise, opor neorrepublicanos e adeptos da public choice ${ }^{l 1}$.

A teoria da escolha pública (TEP) ou public choice delineia uma explicação para o funcionamento do governo baseada na lógica do comportamento econômico individual, racional-maximizante, típico das relações mercantis, contrapondo a visão de homem público altruísta (tantas vezes invocada para justificar o uso do poder por meio do "contrato social") à de homem público egoísta, cujo comportamento interessado precisa ser controlado por mecanismos de punição e recompensa (do mesmo modo que ocorre com o agente econômico concebido pelo pensamento liberal, de cunho hedonista e utilitarista), para que o resultado de sua ação não seja nocivo à sociedade. Os autores clássicos (DOWNS, 1957; BLACK, 1958; BUCHANAN e TULLOCK, 1962; OLSON, 1965; BUCHANAM, 1973) e contemporâneos (por exemplo, NISKANEN 1971; KRUEGER, 1974; NORDHAUS, 1975; HIBBS, 1977; MIGUÉ, 1997; MOE, 1997; SELDON, 1998) desta vertente do pensamento econômico e sociológico criticam veementemente a possibilidade de indivíduos portadores de interesses pessoais e grupais localizados atuarem, de motu proprio, na busca do bem-comum ou do interesse coletivo, tal como previsto em algumas abordagens correntes da Ciência Política (identificadas por MACPHERSON, 1978) e mesmo da Ciência Econômica (especialmente autores desenvolvimentistas e defensores de maiores níveis de intervenção estatal, como keynesianos e cepalinos, por exemplo). Também desconfiam da capacidade do governo de corrigir as falhas de mercado que o desviam das condições de equilíbrio e estabilidade previstas pela teoria econômica (TULLOCK; SELDON, BRADY, 2005).

Para os teóricos da public choice, o sistema eleitoral e os partidos cumprem, na relação política entre representantes (eleitos) e representados (eleitores), papel semelhante ao que o mercado e as firmas cumprem, respectivamente, na relação econômica entre ofertantes (firmas) e demandantes (consumidores). Para eles, no sistema e no processo eleitoral típicos da democracia representativa, os cidadãos-eleitores-contribuintes periodicamente fazem escolhas que definem suas preferências alocativas para os recursos por eles colocados sob a

\footnotetext{
${ }^{11}$ Está em andamento projeto de pesquisa do autor deste artigo analisando a proposta de participação popular nas decisões orçamentárias (orçamento participativo) a partir dos enfoques do neorrepublicanismo e da public choice. Nesta seção, o objetivo é apenas chamar a atenção para a possibilidade e para importância de se avaliar a desejabilidade das IPs do ponto de vista de teorias consagradas pelas ciências sociais, mesmo sem considerar as experimentações em curso, ou seja, mesmo sem recorrer a elementos empíricos.
} 
administração dos políticos e burocratas (aqueles controlando estes); as escolhas recaem sobre cestas de bens públicos anunciadas pelos partidos e seus candidatos (ofertantes a serem escolhidos pelos cidadãos-eleitores-contribuintes demandantes) nos momentos eleitorais.

$\mathrm{Na}$ democracia representativa contemporânea, depreende-se pela teoria da escolha pública, há uma divisão do trabalho (tipicamente weberiana) entre os políticos eleitos (detentores de cargos por meio de legitimidade eleitoral), os burocratas (recrutados por mérito para atuar nas agências governamentais) e os eleitores, cada grupo especializado no desenvolvimento de tarefas específicas dos processos decisórios e de provisão de bens públicos. E essa divisão reveste-se de uma funcionalidade garantidora dos melhores resultados possíveis, desde que haja ampla disseminação de informações, e os sistemas de punição e recompensa funcionem adequadamente, no seu interior. Dessa forma, os custos de decisão e da ação, principalmente os primeiros, são reduzidos dramaticamente, em tese tornando economicamente irracional sistemas e processos de escolha pública e de ação coletiva que pretendam protagonismo do cidadão-eleitor para além da participação em processos eleitorais periódicos ${ }^{12}$. Dessa maneira, metodologias de decisão orçamentária pública que atribuam poder decisório a grupos de indivíduos que não sejam detentores de cargos políticos, legitimados pelo recrutamento eleitoral ou por mérito técnico (tal como ocorre nas práticas que se convencionou chamar de Orçamento Participativo a partir do final dos anos 1980, por exemplo) são, em princípio, contraditórias com a democracia representativa e, acima de tudo, economicamente indesejáveis.

Com efeito, o Orçamento Participativo consiste, na visão da maioria dos seus defensores e proponentes, numa metodologia de decisão orçamentária que aponta na direção de uma democracia para além da representativa liberal, na qual os papéis dos atores envolvidos não são tão clara e esquematicamente estabelecidos e divididos, como pretende a TEP. Na literatura sobre OP encontram-se referências à democracia semidireta (VITALE, 2005), à democracia participativa SANTOS, 2002), à democracia local (ABBERS, 2000), à democracia representativa comunitária (CABANNES, 2005), à democracia deliberativa (BOHMAN e REGH, 1997; ELSTER, 1998; COHEN, 2000), à democracia aprofundada (FUNG e WRIGHT, 2001), à democracia democratizada (PERUZZOTTI, 1998), à democracia redistributiva (SANTOS, 1998, 2002) etc. Com base no mesmo raciocínio destes autores, também os CMGPPs promovem mudanças nas práticas democráticas, apontando na direção da superação da democracia representativa tradicional.

\footnotetext{
${ }^{12}$ Olson (1965) afirma que a não participação em assuntos políticos é uma escolha racional do eleitor, enquanto agente econômico que visa maximização de suas posições. Sua argumentação segue a lógica, apresentada anteriormente por Condorcet, no século XVIII e por Benjamin Constant, no século XIX, segundo a qual a existência de representantes para cuidar de assuntos de interesse coletivo libera os indivíduos para cuidarem de seus assuntos particulares.
} 
Assim, os OP e as CMGPPs são ideias, propostas e experimentações que se movem no campo de uma concepção de sociedade, de governo e de política que, ao negar à democracia representativa tradicional a condição de melhor forma de organização das relações políticas, questiona, indiretamente, a validade da teoria da escolha pública; e se aproxima de forma mais estreita ao neorrepublicanismo (MAIHOFER, 1990; ACKERMAN, 1993; COATS Jr., 1994; SPITZ, 1995; GOODWIN, 1995; VETERLI e BRYNER, 1996; SANDEL, 1996; HABERMAS, 1996; TERCHEK, 1997; PETTIT, 1997; GINER, 1998; ONUF, 1998; BRUGGER, 1999; SKINNER, 1999, 1998; LHANO, 1999; BERLANGA, 1999), cujas teses coadunam com a defesa do aprofundamento democrático dos regimes políticos, por meio de maior participação cidadã - e nas quais os OPs e CMGPPs se encaixam com grande facilidade. E o orçamento público, como as políticas públicas enquanto instrumentos de decisão, são destacados focos de discussão em que a contradição e o confronto entre a TEP e o neorrepublicanismo podem ser explorados, a fim de se obter uma melhor compreensão acerca dos limites e potencialidades de experimentos inovadores nos fazeres governamentais nos quais política e economia rivalizam e se tencionam, mutuamente, como fontes de explicações e de justificativas para os arranjos institucionais existentes e concebíveis.

Se avaliadas na perspectiva da public choice (também conhecida como teoria econômica da democracia), as IPs (principalmente OPs e CMGPPs, densos em aspectos atinentes à alocação de recursos) tendem a ser rejeitadas. Se até mesmo os indivíduos que se apresentam aos demais como altruístas (os candidatos e futuros governantes ou os burocratas que devem, em tese, servir à comunidade), o fazem, apenas, para mascarar seus interesses pessoais, aqueles que se propõem à participação política em busca de solução para seus problemas imediatos (acesso a políticas públicas ou a bens públicos) sequer no discurso podem se apresentar como altruístas. Não há o que esperar da participação cidadã se os agentes todos são egoístas, maximizadores de posições econômicas, atores com comportamento sempre estratégico em defesa de seus próprios interesses.

Já sob a perspectiva neorrepublicana, as IPs são desejáveis a priori, uma vez que seu caráter político (ao invés de econômico, como no caso da public choice) é bastante possibilista: nela o indivíduo não é simplesmente um agente econômico, que se baseia apenas na racionalidade mercantil maximizante; ele é dotado de certos valores e permeável a outros, tendo a capacidade de se envolver em atividades de modo desinteressado (economicamente falando) e disposição para destinar recursos (seu tempo, inclusive) para, em coletividade, buscar um padrão de relacionamento social que considere mais satisfatório, no qual o bem-comum prevaleça. Para os neorrepublicanos, a democracia e o respeito à coisa pública têm valor em si, devendo ser preservadas e aprofundadas. Elas não são apenas instrumentos garantidores da provisão de bens públicos destinados a assegurar ao cidadão-contribuinte, soberano, a adequada 
relação custo-benefício entre as despesas com tributos e os benefícios obtidos com as políticas públicas.

Como se nota, subjaz a cada uma das abordagens uma visão de mundo e uma concepção de homem e de sociedade quase opostas, alicerçadas uma na ciência econômica, outra na ciência política. Mas o que cimenta esses alicerces não é nenhuma dessas ciências, mas sim filosofias políticas distintas. E este fato é uma referência que não se pode perder de vista quando se tem em mãos a tarefa de avaliar experiências de IPs, principalmente quando o objetivo perseguido é teorizar a respeito delas. Mesmo que diga que não, até para si mesmo, todo e qualquer avaliador ou participante de processos avaliativos de inovações como as IPs esposa uma visão de mundo, de indivíduo e de sociedade, na qual a solução do conflito imanente entre indivíduo e sociedade, entre interesse público e privado, encontra alternativas mais individualistas ou mais coletivistas ou comunitárias. Até mesmo as cadeias de causalidade entre variáveis que se procura construir a partir de dados empíricos, nas avaliações, podem ser contaminadas por este elemento condicionante do modo pelo qual o conhecimento se constrói, partindo daqueles que são ao mesmo tempo analistas e objetos de análise. E isso, por sua vez, não elucida-se somente no campo das já aludidas filosofias políticas, mas no âmbito das distintas teorias do conhecimento, a respeito das quais, neste artigo, não se pode dizer mais do que da importância de não serem olvidadas pelos avaliadores de IPs, dada a escassez de espaço e, mais que isso, devido à incompetência dos autores para o aprofundamento desta reflexão.

\section{Um enfoque integrado para a avaliação dos OPs e CGMPPs}

A avaliação das experiências concretas de IPs, como os OPs e os CGMPPs, é uma tarefa de grande complexidade, implicando dificuldades conceituais e metodológicas (PIRES, R. R. C., 2011), muitas vezes envolvendo disputas, até porque "a avaliação como forma de representação de uma realidade implica a própria construção desta realidade a partir de um sistema de referências específico, trazendo consigo umcampo de significados e um conjunto de códigos que lhe são próprios." (CAMPOS, 2011, p. 57). Uma abordagem integrada desta avaliação, que considere os enfoques abordados na seção precedente, pode ser útil para enfrentar a complexidade e administrar as dificuldades e disputas inerentes aos processos avaliatórios de experiências participativas. O diagrama 1 sintetiza esta abordagem, a seguir comentada. 


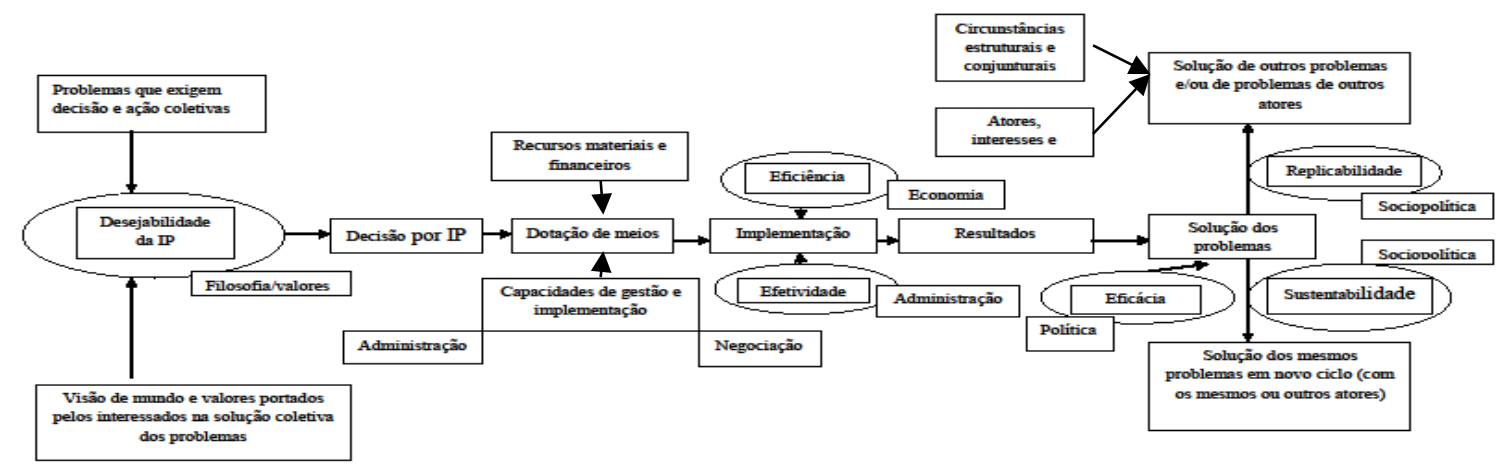

Figura 1 - Visão diagramática integrada dos enfoques para avaliação de IPs

Fonte: elaboração própria

No diagrama 1, os enfoques específicos a serem adotados para proceder à avaliação aparecem nas figuras ovais (eficiência, eficácia, efetividade, sustentabilidade, replicabilidade e desejabilidade). Dependendo de quem avalia e por que motivo o faz, um (uns) ou outro(s) aspecto(s) será(ão) objeto de maior atenção, mas não se deve desprezar totalmente os demais. Quem estiver interessado em adotar o OP, por exemplo, pode se concentrar na análise da replicabilidade, da sustentabilidade e da eficácia, pois se resultarem negativas a decisão pode ser por não tentar a implementação. Uma avaliação estritamente acadêmica poderia começar pela desejabilidade, por outro lado, pois pode-se estar interessado nos aspectos teóricos que levam à defesa da democracia participativa, quando comparada à democracia representativa tradicional (que, por seu turno, tem defensores, alguns dos quais se opõem ao protagonismo de não eleitos em decisões governamentais).

Destaca-se, no diagrama, o caráter multidisciplinar da avaliação, com a apresentação (por meio de figuras retangulares que interceptam as figuras ovais) dos âmbitos disciplinares em que se situam os enfoques aludidos como necessários a um trabalho avaliativo de maior qualidade: enfoque da eficiência, âmbito da economia; efetividade, administração; eficácia, política; sustentabilidade e replicabilidade, sociopolítica; desejabilidade, filosofia/ética/moral.

Percebe-se que o diagrama 1 apresenta os enfoques avaliativos de modo integrado, ao conectá-los a momentos de um processo de implementação de uma IP. Este processo inicia-se quando surge a vontade (ou desejo) de atores propensos à solução dialogada/negociada de problemas com os quais se deparam e que exigem decisões e ações coletivas (enfoque da desejabilidade). A decisão por uma IP é tomada e os meios (recursos materiais e financeiros e 
capacidades de gestão e negociação) para que seja implementada são mobilizados. O manejo dos meios pelos agentes, com efetividade e/ou eficiência leva a resultados, satisfatórios ou não (enfoques da efetividade e da eficiência), que permitem, ou não, solucionar os problemas e/ou atingir os objetivos almejados pela criação da IP (enfoque da eficácia). Se os mesmos modos de decidir e agir puderem ser utilizados em circunstâncias outras, por agentes distintos dos originais, o enfoque da replicabilidade permitirá avaliar. O enfoque da sustentabilidade é um pressuposto da replicabilidade (não se replica o que de início não se sustentou); a sustentabilidade se avalia observando e analisando a permanência da IP por mais de um ciclo de resolução de problemas.

\section{Conclusão}

A avaliação das experiências de OP e das diversas modalidades de IP (no Brasil, especialmente CGMPPs) em andamento nas duas ou três últimas décadas é uma tarefa que se impõe diante da necessidade de se passar da fase de sua acolhida, por razões de fé e esperança (em contexto de redemocratização e reforma do Estado), para uma nova fase, em que elas sejam objeto de avaliações rigorosas e criteriosas, a fim de que possam ser incorporadas ao acervo de proposituras sistematicamente embasadas e teoricamente sustentadas na direção de uma democracia para além da representativa tradicional; ou que sejam descartadas como tentativas insuficientes para isto; ou, ainda, que sejam catalogadas, por ora, como experimentações das quais, por insuficiente sedimentação, não é possível, no atual estágio, tirar conclusões definitivas ou chegar-se a sínteses provisórias com potencial para permitir ou vislumbrar novos avanços teóricos para explicar as relações governo-sociedade em contextos democráticos contemporâneos. Todavia, não se deve perder de vista que, independentemente dos resultados das avaliações sistemáticas, em andamento e por serem feitas, a eclosão dessas IPs, no Brasil, no final do século XX, foi extremamente importante para a retomada e consolidação da democracia, mesmo que seus objetivos pontuais muitas vezes não tenham sido atingidos, pois elas criaram oportunidades e foram instrumentos da mobilização social que mudou a face política do país. Quanto a seu futuro, por outro lado, deve ser iluminado pelas boas avaliações que estão sendo e virão a ser feitas, até porque doravante deixaram de contar com um contexto social e politicamente marcado por mobilizações que possam, por si sós (como no passado recente), sustentar o ímpeto inovador inicial de canais, mecanismos e formas de participação popular em decisões governamentais.

A literatura sobre as avaliações necessárias (sistemáticas e suficientemente isentas, tanto quanto possível em ciências sociais) dos OPs e IPs, após a euforia participativa do final do século XX, já começa a ganhar terreno, sendo as coletâneas de Pires, R. R. C. (2011) e de Avritzer (2010) bons exemplos dessa tendência. O que se tentou neste trabalho foi contribuir com o debate, chamando a atenção para dois aspectos da avaliação necessária dos OPs e IPs: 
primeiro, que toda avaliação que venha a ser feita deve se munir, desde o início, de suficiente clareza acerca dos vários enfoques possíveis para se avaliar IPs em seus resultados e funcionamento, sendo as opções por um ou mais desses enfoques (e correspondentes metodologias) feita com cuidado, além de zelo para perceber que uma avaliação que integre todos os enfoques (tal como ilustrado no diagrama 1 e argumentado na seção 3), é a mais consistente e completa); segundo, que a avaliação sob o enfoque da desejabilidade é a única que comporta a possibilidade de se basear em elementos estritamente teóricos, devido à existência de teorias e escolas de pensamento (social, político e econômico) que, por um lado, advogam contra a participação popular (ou têm forte propensão opositora a ela) nos processos decisórios governamentais (a public choice, por exemplo) e teorias e escolas que, por outro lado, fazem da participação popular um desiderato a ser permanentemente perseguido para melhorar o funcionamento do governo e sua relação com a sociedade civil (o neorrepublicanismo, por exemplo).

No debate teórico, que ao final das contas, se torna filosófico e valorativo, independentemente do status científico de que desfruta, não se pode chegar a quase nada que ultrapasse o campo do normativo, eivado de idéias hegemônicas e contra-hegemônicas; quanto à teoria positiva, dentro dos limites de suas possibilidades em ciências humanas, esta carece, ainda, de muitos estudos (principalmente empíricos) para que possa elevar as IPs à condição de conceito inteiramente integrado ao conhecimento amplamente aceito: a construção de um novo paradigma teórico de democracia ainda está em curso no campo da ciência, embora, ao que parece, as experimentações estejam se acelerando nas últimas décadas, juntamente com o descrédito nas práticas representativas convencionais e com o avanço do discurso pródemocracia participativa, seja no âmbito acadêmico (como atesta a literatura de cunho neorrepublicano), seja no âmbito político, principalmente, como denotam numerosos discursos e documentos institucionais (como, por exemplo CLAD, 2009; OCDE, 2001).

Entre o teórico e o prático, o normativo e o positivo, o politicamente pragmático e o analiticamente crítico-reflexivo, encontra-se em estado de gasoso para líquido o conhecimento científico sobre as instituições participativas, sem que se saiba, até agora, se virá a tornar-se sólido e, assim, soldar-se aos demais aparatos analíticos das ciências sociais, ou terminar colidindo com eles ou alguns deles. Independentemente do que venha a ocorrer, as avaliações empíricas sobre o funcionamento e os resultados das IPs são necessárias, mas não podem prescindir de debates no campo dos valores, pouco perscrutáveis utilizando-se metodologias de pesquisa quantitativas e/ou focadas exclusivamente na busca de elos de causalidade. 


\section{Referências}

ABERS, R. A. Inventing Local Democracy: Grossrooth Politics in Brazil. Boulder, Colorado: Lynne Rienner Publishers, 2000.

ACKERMAN, B. We the people: foundations. Cambridge, MA: Harvard University Press, 1991.

ALEGRETTI, G. Orçamentos Participativos na Itália: inovações dentro de um quadro em rápida transformação. In: SILVA, E.M. da; CUNHA, E. S. M. (Org.). Experiências internacionais de participação. Belo Horizonte/São Paulo: UFMG/Ed. Cortez, 2009. p. 67-110.

AVRITZER, L. Instituições participativas e desenho institucional. Opinião Pública, Campinas, v. 14, p. 43-64. jun. 2008.

AVRITZER, L. (Org.). Experiências nacionais de participação. São Paulo: Cortez, 2010.

AVRITZER, L. A qualidade da democracia e a questão da efetividade da participação: mapeando o debate. In: PIRES, R. R. C. (Org.). Efetividade das instituições participativas no Brasil: estratégias de avaliação. Brasília: IPEA, 2011. p. 13-25.

AVRITZER, L.; NAVARRO, Z. (Org.). A inovação democrática no Brasil: o orçamento participativo. São Paulo: Cortez, 2003.

AVRITZER, L.; WAMPLER, B. The expansion of Participatory Budgeting in Brazil. An Analysis of the current cases based upon design and socio-economic indicators. In: AVRITZER, L.; WAMPLER, B. (Org.). Research Report The World Bank/Municipal Development Program. Belo Horizonte: dec., 2008. Disponível em: <http://www.redeopbrasil.com.br/html/biblioteca/relatorio_banco_mundial_censo_op.pdf>. Acesso em: 20 jan. 2012.

BerlangA, J. L. V. Res Publica: los fundamentos normativos de la politica. Madrid: Akal, 1999.

BLACK, D. The theory of commitees and election. Cambridge: Cambridge University Press, 1958.

BOHMAN, J.; REGH. W. Deliberative democracy: essays on reason and politics. Massachusetts: Massachesetts Institute of Tecnology, 1997.

BRESSER-PEREIRA, L. C.; WILHEIM, J.; SOLA, L. (Org.). Sociedade e Estado em transformação. São Paulo/Brasília: Ed. UNESP/ENAP, 1999.

BRUGGER, B. Republican Theory in Political Thouhgt: virtous or virtual?. Londres: MacMillan Press, 1999.

BUCHANAN, J. M. La hacienda publica en un proceso democratico. Madrid: Aguilar, 1973.

BUChanan, J. M.; TUllOCK, G. The Calculus of Consent. Ann Arbor: Universit of Michigan Press, 1962.

CABANNES, Y. Presupuesto participativo y finanzas locales. Porto Alegre: Programa de Gestión Urbana-ALC; UN-HABITAT, 2004. Disponível em < http://www.rapp.gov.ar/descargas/4.\%20CABANNES.pdf>. Acesso em 05 mai 2013. 
CAMPOS, G. A. G. de. Participação e representações não avaliativas: a produção de significados nas experiências participativas. In: PIRES, R. R. C. (Org.). Efetividade das instituições participativas no Brasil: estratégias de avaliação. Brasília: IPEA, 2011. p. 53-64.

CARVALHO, A. I. Conselhos de saúde no Brasil: participação cidadã e controle social. Rio de Janeiro: Fase, 1995.

CLAD. Carta Iberoamericana de Participación Ciudadana en la Gestión Pública. Caracas: CLAD, 2009. Disponível em < http://www.clad.org/documentos/declaraciones/cartaiberoamericana-de-participacion-ciudadana>. Acesso em: 26 out. 2011.

COATS Jr., W. J. A Theory of Republican Character and Related Essays. London: Susquehanna University Press, 1994.

COHEN, J. Procedimiento y sustancia en la democracia deliberativa. México, Metapolítica, v.4, n. 14, p.24-47, abr./jun.

COSTA, D. Vinte anos de Orçamento Participativo: análise das experiências em municípios brasileiros. São Paulo, Cadernos Gestão Pública e Cidadania, São Paulo, v. 15, n. 56, p. 8-28, 2010.

DAGNINO, E. (Org.). Sociedade civil e espaços públicos no Brasil. São Paulo: Paz e Terra, 2002.

DIAS, N. Os Orçamentos participativos em Portugal: uma nova dinamização na democracia local no país. In: SILVA, E.M. da; CUNHA, E. S. M. (Org.). Experiências internacionais de participação. Belo Horizonte/São Paulo: UFMG/Ed. Cortez, 2009. p. 111-132.

DOWNS, A. An economic theory of democracy. New York: Harper \& Row, 1957.

ELSTER, J. Deliberative democracy. Cambridge: Cambridge University Press, 1998.

FUNG, A.; WRIGHT, E. O. Deepening democracy: inovation in empowered participatory governance. Politics \& Society, Stoneham, v. 29, n. 1, p. 5-41, March 2001.

GINER, S. Las razones del republicanismo. Claves de Razón Pratica, Madrid, n. 81, p. 2-13, 1998.

GOHN, M. da G. Conselhos Gestores e participação sociopolítica. São Paulo: Ed. Cortez, 2001.

GOODWIN, C. S. A Resurrection of the Republican Ideal. Lanham, Mariland/ London: The University Press of America, 1995.

GUIMARÃES, C. A. S. et. alli. Conselhos Gestores na Educação: perfil, discurso, funcionamento. Recife: FJN/Ed. Massangana, 2009.

HABERMAS, J. Between Facts and Norms, Contributions to a Discourse Theory of Law and Democracy. Cambridge, Ma.: The MIT Press, 1996.

HERZBERG, C. Von der Bürger- zur Solidarkommune. Lokale Demokratie in Zeiten der Globalisierung. Hamburg: VSA-Verlag, 2009. 
HIBBS, D. A. Political parties and macroeconomic policy. American Political Science Review, Cambridge, n. 71, n. 4, p. 1467-1487, Dec. 1977.

KRUEGER, A. The political economy of the rent-seeking society. American Economic Review, Cambridge, n. 65, n. 3, p. 191-303, Jun. 1974.

LLANO, A. Humanismo Cívico. Madrid: Ariel, 1999.

MACPHERSON, C. B. A democracia liberal: origens e evolução. Rio de Janeiro: Zahar, 1978.

MAIHOFER, W. The ethos of the republic and the morality of politics, 1990. In: BOCK, G.; SKINNER, Q.; VIROLI, M. (Ed.). Machiavelli and Republicanism. New York: Hill and Wang, 1999. p. 283-292.

MIGUÉ, J-L. Public Choice in a Federal System. Public Choice, Amsterdam, v. 90, n. 1-4, p. 235-254, Mar. 1997.

MOE, T. M. The positive theory of public bureaucracy. In: MUELLER, D. (Ed.). Perspectives in Public Choice. Cambridge: Cambridge University Press, 1997. p. 455-480.

NISKANEN, W.A. Bureaucracy and Representative Government. Nova York: AldineAthlerton, 1971.

NORDHAUS, W. The political business cycle. Review of Economic Studies, Oxford, n. 42, p. 169-190, Apr. 1975.

OCDE. Citizens as partners: information, consultation and public participation in policymaking. Paris: OCDE, 2001.

OLSON, M. The Logic of Collective Action: Public Goods and the Theory of Groups. Cambridge: Harvard University Press, 1965.

ONUF, N. G. The Republican Legacy in International Thought. Cambridge: Cambridge University Press, 1998.

PERUZZOTTI, E. Democratizing democracy: political culture, public sphere and collective learning in post-dictatorial Argentina. Mimeo, 1998.

PERUZZOTTI, E. As políticas de inovação institucional: a implementação do Orçamento Participativo na cidade de Buenos Aires. In: SILVA, E.M. da; CUNHA, E. S. M. (Org.). Experiências internacionais de participação. Belo Horizonte/São Paulo: UFMG/Ed. Cortez, 2009.

PETTIT, P. Republicanism. A Theory of Freedom and Government. Oxford: Oxford University Press, 1997.

PINEDA NEBOT, C. "Los Presupuestos Participativos en España: un nuevo balance" en la Revista de Estudios de la Administración Local y Autonómica, Madrid, n. 311, p. 277-303, sep.-dic. 2010.

PINEDA NEBOT, C.; PIRES, V. Tipología de los Presupuestos Participativos (PP) españoles. Anais... Encontro Nacional da Associação de Pós-Graduação e Pesquisa em Administração, 35, Rio de Janeiro. XXXV EnANPAD. Rio de Janeiro: ANPAD, 2011. 
PIRES, R. R. C. (Org.). Efetividade das instituições participativas no Brasil: estratégias de avaliação. Brasília: IPEA, 2011.

PIRES, V. Orçamento Participativo: o que é, para que serve, como se faz. Barueri: Ed. Manole, 2001.

PIRES, V. Transparência, participação e orçamento participativo: reflexões a partir do caso brasileiro. Temas de Administração Pública, Araraquara, v. 4, n. 5, 2009. Disponível em: $<$ http://master.fclar.unesp.br/Home/Departamentos/AdministracaoPublica/RevistaTemasdeAdm inistracaoPublica/pires5.pdf >. Acesso em: 21 mar. 2012.

PIRES, V.; MARTINS, L. de J. Orçamento Participativo (OP) após vinte anos de experiências no Brasil: mais qualidade na gestão orçamentária municipal? Anais... Encontro Nacional da Associação de Pós-Graduação e Pesquisa em Administração, 35, 2011, Rio de Janeiro. XXXV. EnANPAD. Rio de Janeiro: ANPAD, 2011.

PIRES, V.; SILVA, R. G. da. Orçamento Participativo: a opinião de políticos do interior paulista em 1999. Revista Acadêmica Multitemática, São Paulo, ano XI, n. 30, p. 315-323, 2004 ,

RIBEIRO, A. C. T.; GRAZIA, G. de. Experiências de Orçamento Participativo no Brasil: período de 1997 a 2000. Petrópolis: Ed. Vozes, 2003.

SANDEL, M. Democracy's Discontent, America in Search of a Public Philosophy. Cambridge: The Belknap Press of Harvard University Press, 1996.

SANTOS JÚNIOR, O. A.; RIBEIRO, L. C. Q.; AZEVEDO, S. (Org.). Governança democrática e poder local: a experiência dos conselhos municipais no Brasil. Rio de Janeiro: FASE/Revan, 2004.

SELDON, A. The dilemma of democracy: the political economics of over-government. London: Institute of Economic Affairs, 1998.

SKINNER, Q. Liberty before Liberalism. Cambridge: Cambridge University Press, 1998.

SKINNER, Q. The republican ideal of political liberty. In: BOCK, G.; SKINNER, Q.; VIROLI, M. (Ed.). Machiavelli and Republicanism. New York: Hill and Wang, 1999. p. 293-309.

SANTOS, B. de S. Democratizar a democracia: os caminhos da democracia participativa. Rio de Janeiro: Civilização Brasileira, 2002.

SANTOS, B. de S. Budgetings in Porto Alegre: Towards a Redistributive Democracy. Politics and Society, Stoneham, v. 26, n. 4, p. 461-510, Dec. 1998.

SPITZ, J. F. La liberté politique. Paris: PUF, 1995.

TATAGIBA, L. Os Conselhos Gestores e a democratização das políticas públicas no Brasil. In: DAGNINO, E. (Org.). Sociedade civil e espaços públicos no Brasil. São Paulo: Paz e Terra, 2002. p.47-103.

TERCHEK, R. Republican Paradoxes and Liberal Anxieties. Lanham: Boulder, 1997.

TULLOCK, G.; SELDON, A.; BRADY, G. Falhas de governo: uma introdução à teoría da escolha pública. Rio de Janeiro: Instituto Liberal, 2005. 
VAZ, A. C. N. Da participação à qualidade da deliberação em fóruns públicos: o itinerario da literatura sobre conselhos no Brasil. In: PIRES, R. R. C. (Org.). Efetividade das instituições participativas no Brasil: estratégias de avaliação. Brasília: IPEA, 2011. p. 91-108.

VETERLI, R.; BRYNER, G. In Search of the Republics, Public Virtue and the Roots of the American Government. Lanham: Roman and Littlefield, 1996.

VITALE, D. Democratizando o processo orçamentário: a experiencia do Orçamento Participativo nos municipios brasileiros. In: BRASIL. Secretaria do Tesouro Nacional. Finanças Públicas - IX Prêmio Tesouro Nacional: Monografias. Brasília: ESAF, 2005. p. 659-724.

Artigo recebido em: 04/05/2013 